\title{
A lifetime of experience: modeling the labour market and family histories of older adults in Britain
}

\author{
Laurie M Corna \\ Department of Social Science, Health and Medicine, King's College London \\ laurie.corna@kcl.ac.uk
}

Amanda Sacker

ESRC International Centre for Lifecourse Studies in Society and Health, University College London

(Received October 2012 Revised January 2013)

\section{Abstract}

In the context of the life course, it is difficult to understand outcomes and relationships among older adults independently from the experiences that precede them. In this paper, we use a latent class approach to model interdependent labour market and family experiences from late adolescence to retirement age among a group of older adults in Britain. We also assess how these experiences are related to economic resources and health at age 65. The data come from the retrospective life history files of the British Household Panel Survey, and our sample included older adults born between 1927 and 1940. A two-stage latent class model facilitates assessment of the most likely combinations of work and family roles at particular ages across the life course, and the pathways that link these experiences over time, incorporating the effects of gender and birth cohort. Model fit indices and theoretical considerations suggested that five latent life paths broadly characterized the work and family experiences of older adults in this sample. They were distinguished by gender, labour market and family care activities, marital status and the presence of children in the household. We noted better economic resource and mental health outcomes among the latent life pathways describing predominantly male experiences, but also note the heterogeneity of women's experiences and their implications for economic and health outcomes at retirement age. We discuss the applicability of the latent class approach for modeling work and family histories for future research.

Keywords: labour market histories; family roles; life course; welfare state; latent class models

\section{Introduction}

Understanding the dynamic interaction between individual biography, structural context, and historical time is fundamental to the life course perspective (Dannefer, 2003; Elder, 1985; O'Rand, 1996). Trajectories that unfold over time and the transitions that punctuate them are shaped not only by individual choices and preferences, but also by the structural opportunities and constraints (social policies, safety nets and other events) that contextualize them. The complexity, heterogeneity, and dynamic nature of the life course has rendered its empirical assessment complex, due to both the limited availability of longitudinal data addressing life course issues and appropriate analytical approaches. Yet, a better understanding of how individual trajectories in multiple life course domains unfold over the life course has the potential to address numerous issues in the field of life course research, such as how holistic life course experiences differ across social groups and across time, the extent to 
which particular contexts shape life course experiences, and how life course experiences influence important outcomes in later life, such as health and economic resources.

The central aim of this paper is to apply a latent class approach to model interdependent experiences in the labour market and the family, from late adolescence to retirement age among a group of older adults in Britain. The relationship of these experiences to economic and health outcomes at retirement age is also assessed. In what follows, we provide a brief overview of the conceptual underpinning of the analysis - the life course in context-before moving on to discuss the latent class approach adopted in this work.

\section{The life course in context}

The study of trajectories in multiple life course domains, and the transitions that shape them, is central to life course research (Elder, 1985; George, 1996). Trajectories do not unfold in isolation; rather, the various social roles that individuals occupy as workers, partners and parents are interwoven to create what Elder and colleagues refer to as 'social pathways' (Elder, Kirkpatrick Johnson, \& Crosnoe, 2003). This idea is reflected in the study of the interdependencies of various roles (e.g., parenthood, labour market activity, marital status) during developmental periods, such as the transition to adulthood (Amato, Landale, Havasevich-Brooks, \& Booth, 2008; Macmillan \& Copher, 2005; Schulenber \& Schoon, 2012), demonstrating the implications of role occupancy in particular domains for experiences in others. For example, early parenthood for women is often accompanied by early school leaving and more limited labour market opportunities (Macmillan \& Eliason, 2003). Life course scholars also acknowledge the interdependencies within the family-the idea of 'linked lives'- recognizing that decisions about work and family life are most often made in tandem with those of spouses, and in response to care giving responsibilities for children or other dependants (Elder et al., 2003).

The life course perspective is also cognizant that individual experiences unfold within a set of opportunities and constraints defined, in part, by social policies and provisions (Elder et al. 2003; Leisering 2003; Marshall and Mueller 2003). This does not trivialize individual agency, but seeks to understand the very institutions that give rise to and constrain individual experiences. Doing so recognizes the role of the welfare state in shaping life course outcomes, and emphasizes how various welfare state regimes differ with regard to life course policy, reflected in varying levels of state intervention and protection, and diverse configurations of state and private responsibility. This includes, but is not limited to, the ways in which institutional or structural contexts create gendered opportunities with respect to work and family roles (Lewis 1992; O'Connor, Orloff, \& Shaver, 1999).

Current cohorts of older adults in Britain lived out their working years in the decades following World War II - a period of history that was, at least until the mid-1970s, characterized by strong support for the male breadwinner / female homemaker family model. This model positioned men as primary wageearners for the household and women as primary care providers (Creighton 1999; Lewis 2001; O'Connor et al. 1999; Pedersen 1993), firmly entrenching the gender division of labour within and outside the formal labour market. State support for these arrangements included legislated minimum wage rates and family (i.e., male) wages, taxation policies that discouraged women's employment, and government subsidies for the household to supplement the family wage (Creighton, 1999). Policy pertaining to public child care was limited and wage replacement rates for care absences from the labour market were meagre or non-existent ( $O^{\prime}$ Connor et al. 1999), making it difficult for women with caring responsibilities to participate in the labour market on an equal footing with men. The social policies and provisions of post-World War II Britain contextualize observed patterns of work and family involvement over time and provide insight as to how experiences may differ by gender.

The life course perspective provides a conceptual framework for bridging individual experiences and the contexts in which they occur. It is the empirical assessment of these experiences that, until more recently, has been less developed. Indeed, considerable methodological advances in life course research have been made in the last 10-15 years, including the application of latent class models to assess the multi-dimensionality, heterogeneity and 
dynamic nature of life course experiences (Amato et al., 2008; Macmillan \& Eliason, 2003; Macmillan \& Copher, 2005). A longitudinal latent class approach conceptualizes individual life course experiences as probabilistically interlocked trajectories that unfold over time. This is accomplished through the identification of latent social role configurations at various ages across the life course and the latent life paths that link these configurations over time (Macmillan \& Eliason, 2003). Unlike other analytical approaches commonly used in life course research, such as event history models, latent class models do not require the specification of independent and dependent variables or assume a homogenous trajectory from which individuals deviate (Aisenbrey \& Fasang, 2010; Feldman, Masyn, \& Conger, 2009).

Latent class models have been used previously to model work and family transitions into adulthood (mid-adolescence to early thirties) (Macmillan \& Eliason, 2003), the timing of childbearing and women's transitions to adulthood (Macmillan \& Copher, 2005) and in cross-sectional comparative research on role configurations in young adulthood (e.g., Maggs, Jager, Patrick, \& Schulenberg, 2012; Räikkönen, Kokko, Chen, Pulkkinen, 2012), but have not yet been applied to the study of multiple life course domains over more substantial periods of time. Moreover, although previous work has stratified its analyses to look at role configurations among particular social groups (e.g., Macmillan \& Copher, 2005), group membership (e.g., gender) has not been considered as a predictor of the social role configurations that comprise life course experiences. Given the centrality of gender, as well as birth cohort, to roles in the labour market and the family, and the ability for latent class models to incorporate covariates, their inclusion is important.

In this paper, we first use a two-stage latent class model and retrospective life course history data from the British Household Panel Survey to model interdependent work and family experiences. This extends the work of Macmillan and Eliason (2003) in two important ways: (1) we consider a much longer period of the life course (age 19-64) to capture the interlocked trajectories of labour market involvement, occupational class, marital/partner histories and childbearing from late adolescence to retirement age; and (2) we include gender and birth cohort as covariates in the first stage of the analysis. Covariates not only improve the classification of individuals (Magidson \& Vermunt, 2004), but also allow us to see how gender and birth cohort shape life course experiences in these domains. We next assess the relationship between the derived life course experiences and outcomes of interest at retirement age (health, economic resources). In what follows, an overview of latent class models is provided, followed by a discussion of the two-stage approach applied in this work.

\section{Latent Class Analysis and the Two-Stage Model}

Latent class analysis (LCA) is a type of mixture modelling where, similar to factor analysis, unobserved latent classes account for the relationships between observed categorical (dependent) variables (Lazarsfield \& Henry, 1968). However, unlike factor analysis, a latent class approach classifies individuals rather than variables. Observed categorical variables are used to estimate the parameters of a measurement model, including item parameters and class probability parameters. Item parameters refer to the conditional item probabilities that are class-specific and provide information on the probability of an individual in that class endorsing a particular item. Class probability parameters, or the unconditional probabilities, specify the relative prevalence of each class (Nylund, Asparouhov, \& Muthén, 2007). For example, four (observed) nominal latent class indicators A, B, C, and $D$, would produce the following model:

$$
\pi_{i j k l t}=\pi_{t}^{X} \pi_{i t}{ }^{A / X} \pi_{j t}{ }^{B / X} \pi_{k t}{ }^{C / X} \pi_{\mid t}{ }^{D / X},
$$

where $\pi_{i j k l t}$ represents the likelihood function where $\pi_{t}^{x}$ denotes the unconditional probability of being in latent class $t=1,2, \ldots, T$ of latent variable $X ; \pi_{i t}{ }^{A \mid X}$ represents the conditional probability of obtaining the $i$ th response to observed variable $A$ (where possible response categories include $i=1,2, \ldots$ ) given membership in latent class t. Similarly, $\pi_{j t}{ }^{B \mid X}, \pi_{k t}{ }^{C \mid X}$, and $\pi_{/ t}{ }^{D \mid X}, j=1,2, \ldots, J, k=1,2, \ldots, K$, and $l=1,2, \ldots, L$, denote the corresponding conditional probabilities for items $B, C$, and $D$ respectively (Macmillan \& Eliason, 2003). In short, these conditional probabilities indicate the distribution of the observed 
variables within each latent class. LCA assumes that each observation is a member of one, and only one, of $T$ latent classes. This assumption of local independence suggests that conditional on latent class membership, the observed variables are mutually independent of each other (Magidson \& Vermunt, 2004).

One of the goals of LCA is to determine the smallest number of classes that fit the data well and account for the associations among the observed variables. Typically, a baseline one-class model is first assessed. Assuming that the null model does not provide a good fit to the data, a model with two classes is next assessed. The number of classes is increased by one in each successive model until adequate model fit is obtained. Observed covariates can be used to predict latent class membership, and are expressed as a multinomial regression of the categorical latent variable $X$ on the covariates, in comparing each class ( $T-1)$ to a reference class in an T-class model.

The two-stage LCA extends the traditional latent class model described above. Applied to modeling life course experiences in the labour market and the family, the two-stage approach begins by modeling the dominant (latent) role configurations of work and family life at selected ages across the life course. Role configurations refer to the constellation of roles that individuals occupy at any one point in the life course (Macmillan \& Eliason, 2003). Using the results from the first stage, the second stage involves running a second LCA to determine how these role configurations at selected ages are linked over time (Macmillan \& Eliason, 2003). The resulting latent pathways represent the progression of individuals through a number of role configurations across the life course.

More formally, in the two-stage LCA, observed roles that individuals occupy at various points or ages $(t)$ in the life course, denoted as $i(t)$, are embedded in unobserved, or latent role configurations, denoted $m(t)$. These latent role configurations further constitute latent life pathways, denoted j. As specified by Macmillan and Copher (2005), the joint probability of experiencing transitions through agegraded observed role configurations $i(1)$ to $i(\mathrm{~T})$ given age-graded latent role configurations $m(1)$ to $m(T)$ (where $t=1,2, \ldots T$ ), and latent life pathways $j$ is given by:

$$
\pi_{i(1) \ldots i(T) m(1) \ldots m(T) j}=\pi_{i(T) \mid m(T)} \pi_{m(1) \mid j} . . \pi_{m(T) \mid j} \pi_{j}
$$

where $\pi_{i(1) \ldots i(T) m(1) \ldots m(T) j}$ is the joint probability, $\pi_{i(t) \mid m(t)}$ is the conditional probability of observed role configuration $i(t)$ given latent role configuration $m(t)$ at each age $t, \pi_{m(t) \mid j}$ is the conditional probability of latent role configuration $m(\mathrm{t})$ given pathway $j$, and $\pi_{j}$ is the probability of pathway $j$ within the population.

Estimation of these probabilities using traditional LCA is not feasible. Obtaining full information maximum likelihood (FIML) estimates would require the construction of the full transition matrix for all observed role configurations over the entire set of age points (Macmillan \& Eliason, 2003). In this work, ten age points with four detailed nominal latent class indicators are assessed. This would produce a matrix that would be unacceptably large with many empty cells. Thus, the two-stage LCA offers an alternative by first articulating latent role configurations from the observed roles that individuals occupy in multiple domains at various points across their life course. Once this is accomplished, traditional LCA assumptions are modified to restrict the observed role configurations and latent life paths to interact exclusively through the latent role configurations, rather than estimating latent life pathways using the observed roles in the various life course domains (Macmillan \& Eliason, 2003). That is, the latent life paths are based entirely on the latent role configurations articulated in the first stage of the analysis.

Using Mplus(v.5) software, the first stage of the two-stage model uses traditional LCA to calculate the FIML estimates for the conditional probabilities of observed roles and positions given latent role configuration (or latent class) membership at 5-year age intervals beginning at age 19. In these models, gender (female) and birth cohort are included as predictors of role configuration membership (Figure 1). For each latent class model, we specified 2000 random sets of starting values and 50 optimizations for the final stage. This ensures that the best log likelihood is replicated and that solutions are not derived from local maxima. At each age point, Mplus calculates individual posterior probabilities for 
each class and uses probabilistic assignment to classify each respondent to their appropriate latent role configuration. Simulation studies regarding the assignment of individuals to their most likely class for use in subsequent analyses support the approach when the entropy (discussed below) is high (greater than 0.80) (Clark \& Muthén, 2009), which was the case in this study. In the next stage, a second LCA is run that estimates the conditional maximum likelihood estimates of latent pathway probabilities of role configurations over time (Figure 2).

Figure 1. Traditional LCA with covariates to model latent role configurations (LRC) in four life course domains [labour market activity (LMA), occupational class (OC), marital status (MS), and parenting status of dependent children $(\mathrm{CH})]$ at various points across the life course

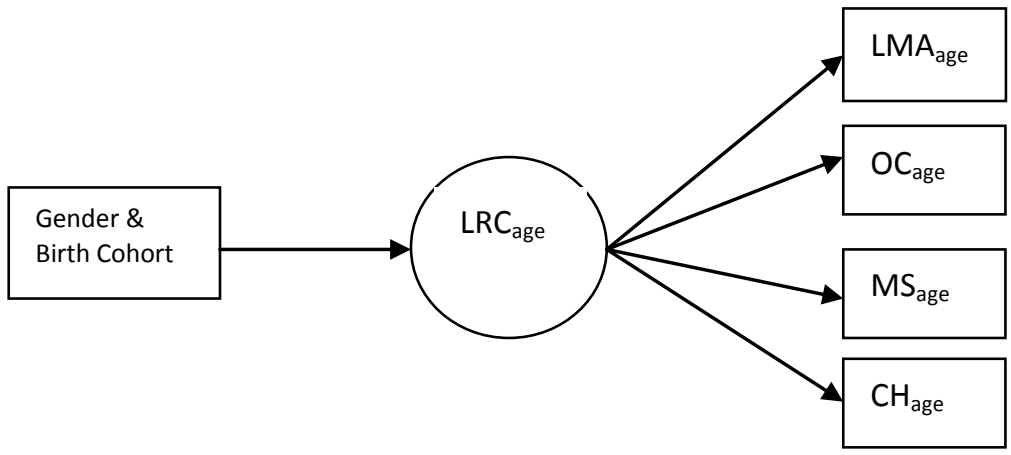

Figure 2. Modeling latent life paths (LLPs) in the second stage from the latent role configurations (LRC) derived in the first stage

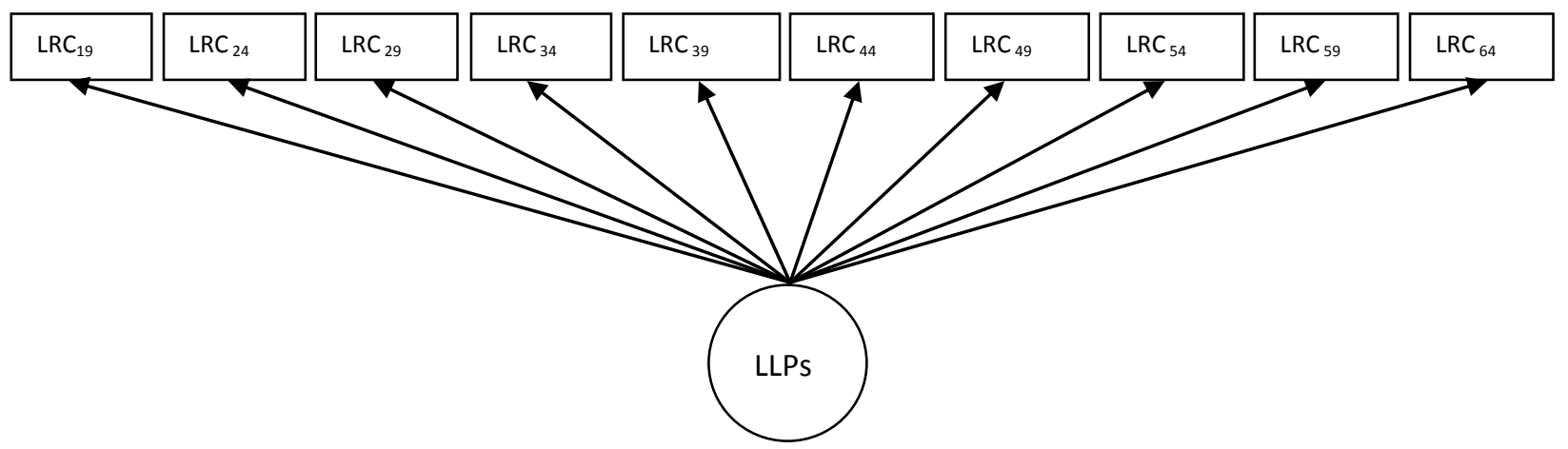

Assessment of model fit: determining the number of classes

There is not a commonly accepted fit statistic for deciding on the optimal number of classes in LCA (Nylund et al., 2007). Rather, this decision must be made on the basis of theoretical and substantive knowledge and a number of commonly accepted fit statistics. Here, the Bayesian Information Criterion (BIC) and an alternative likelihood ratio test (LRT) the Lo-Mendell-Rubin LRT (Lo, Mendell, \& Rubin,
2001) - were used to assess the fit of nested models at both stages of the analysis. While not an index of model fit, the adequacy of model classification as indicated by the entropy index is also used in selecting the optimal number of latent role configurations and latent life paths.

BIC. The BIC calculated in Mplus is defined as $2{ }^{*} \log$ likelihood $+r^{*} \log n$, where " $r$ " is the number of parameters in the model and " $\mathrm{n}$ " is the sample size (Muthén \& Muthén, 2010). The model with the 
lowest BIC value is thought to provide the best fit while penalizing for model complexity.

Lo-Mendell-Rubin Likelihood Ratio Test (LMRLRT). The LMR-LRT compares an estimated (t-class) model with its neighbouring model with one less class ( $t-1$ class model) and provides a $p$-value that can be used to determine if the inclusion of an additional class provides an improvement in model fit (Lo et al., 2001). The LMR-LRT uses an approximation of the distribution for the difference between the two log likelihoods rather than the chi-square distribution (Nylund et al., 2007). The calculated $p$-value represents the probability that the data could have been generated by the model with one less class. A low $p$-value suggests that the $t-1$ model is rejected in favour of the $t$-class model (Muthén \& Muthén, 2010).

Entropy index. While not an indicator of model fit, the entropy index provides an indication of classification quality. While specific cut-points do not exist to indicate good classification, an entropy value that approaches 1.0 is favourable (Celeux \& Soromenho, 1996).

\section{Assessing the relationship between latent life paths and outcomes in later life}

To address the second aim of this paper-to determine whether economic and health outcomes in later life differ across the latent life path groups-we ran a series of Anovas (Analyses of variance), testing mean differences in three measures of income and two measures of health (described below).

\section{Data}

The data come from the British Household Panel Survey (BHPS), an ongoing, nationally- representative sample of approximately 5,500 households and 10,000 individuals from over 250 areas of Great Britain. The survey began in 1991 and households were selected using a two-stage stratified systematic sampling method. Household members over the age of 16 are re-interviewed annually, providing 18 waves of data to date (Taylor, Brice, Buck, \& Prentice-Lane, 2010). Panel members who were born between 1927 and 1940 were included in the sample $(\mathrm{N}=1,552)$. Health and income data were collected prospectively during the annual interviews. Retrospective data collected at Waves 2 and 3 (1992 and 1993) supplemented the annual files and included details on labour market activities, occupational class, partnerships and children from when respondents first left full-time education. In this work, retrospective data from age 19-64 were used). For labour market and occupational class spells, we used the work-life history file that corrected for any date inconsistencies (Maré, 2006).

Labour Market Histories \& Occupational Class Respondents were asked about all employment spells since first leaving full time education. The start and end dates, and duration of each spell were recorded. Distinct spells are defined by a change in type of labour market activity (Taylor et al., 2010). Using the start and end dates, spells of the following activities were constructed: (1) self-employment; (2) full-time employment; (3) part-time employment; (4) unemployment; (5) retirement; (6) family care (including maternity leave); and (7) involvement in an "other" activity. The latter included returning to fulltime education, participating in a government training program, or being on sick leave. The modal monthly labour market activity for any given year was assigned to the entire year.

The data included the 1990 Standard Occupational Classification (SOC) codes for each labour market spell, but did not contain the newer National Statistics-Socio-Economic Classification (NSSEC) now commonly used as an occupation-based measure of socioeconomic position in Britain (Rose \& Pevalin, 2002). To overcome this, the 1990 SOC code was converted to the NS-SEC using the guidelines provided in the "Reduced Method NS-SEC Analytic Classes" derivation table (Office for National Statistics, 2005). The final variable for occupational position was the three-class version of the NS-SEC, which distinguished between: (1) managerial and professional occupations; (2) intermediate occupations; and (3) routine and manual occupations. A carry-over imputation was used to assign an occupational class to periods of labour market absence and the modal occupational class in any given year of age was assigned to the entire year.

Marriage and Cohabitation Spells The month and year of the start of each legal marriage, and where applicable, the month and year of divorce, separation, or widowhood for each union were used 
to construct marital spells. Cohabitation spells were similarly constructed. The "marriage/cohabitation" status reported at the time of the respondent's birthday each year was applied to the entire year. Limitations in the data precluded using the modal monthly marital / cohabitation status to define respondents' status for the entire year. The possible categories included: (1) never married; (2) married or cohabiting; and (3) separated, divorced, or widowed.

\section{Dependent Children in the Household} Dependent children were defined as being younger than 16 years old. The year of birth or the date at which the child joined the household, and either the date at which the child left the household or the date of his/her $16^{\text {th }}$ birthday (whichever occurred first), were used to define their presence in the household (coded 1=yes, $0=$ no). The presence or absence of children at the time of the respondent's birthday each year was assigned to the entire year. Limitations in the data precluded a more detailed analysis of the age at which children actually left home, as well the use of the modal monthly status to classify the presence of children for the entire year.

Covariates Gender and birth cohort were included in the first stage of the analysis as covariates. Females were compared to males, and year of birth was coded as a series of dummy variables: (1) born 1932-1936 (coded 1=yes, 0=no); and (2) born 1937-1940 (coded $1=$ yes, $0=$ no). Respondents born between 1927 and 1931 served as the reference birth cohort.

In the second stage of the analysis, we analyze the relationship between the latent life paths and a number of economic and health outcomes.

Economic Resources Benefit Income measured total income from all state benefits, including the Basic State Pension, received during the previous year. Pension Income included income from all non-state pensions, savings and investments, and rental income from boarders and lodgers received during the previous year. Finally, labour income was the total of all labour income earned during the previous year. We opted to use income collected at age 66 , since these figures reflect income over the previous $\left(65^{\text {th }}\right)$ year. All income measures were converted to pound sterling values in 2005 using the Consumer Price Index (Office for National Statistics, 2012).

Health We assessed two measures of health: mental health and an index of chronic health problems. Mental health was assessed using the 12-item General Health Questionnaire (GHQ-12) (Goldberg \& Williams, 1988; Pevalin, 2000). Possible scores range from 0 to 36, with higher scores indicating greater mental health problems. Respondents were also asked whether or not they had been diagnosed with ten health problems (arthritis, visual impairment, hearing impairment, chest / breathing problems, heart problems or high blood pressure, stomach problems, diabetes, epilepsy, migraine headaches or an 'other' health problem). Positive responses to items were summed to form an index of co-morbid health problems (range $=0$ to 10). We examine these health outcomes at age 65 .

\section{Results}

A total of 1,552 respondents contributed information to the retrospective life course histories. Just over one half $(52 \%)$ were women, and the average age of the respondents at the time when their retrospective information was collected was 57 years (s.d. $=4$ years). Table 1 provides the distribution of the labour market activities, occupational class, marital status and parenthood status of respondents at selected ages (ages 19-59 in 10-year intervals).

The first step in the analysis was the assessment of the fit of the latent role configurations (LRCS) of work and family life at each five-year age interval (Table 2). Gender and birth cohort were included as covariates to predict membership in the LRCs. Since the inclusion of covariates requires a model with a minimum of two latent classes, one-class models were not considered. The model that provided the best fit and adequately captured the configurations of work and family roles at each age is presented in bold type. 
Table 1. Distribution of Observed Labour Market Activities, Occupational Class, Marital Status and Dependent Children at ages 19-59, $\mathrm{N}=1,552$

Labour Market Status:

Self-employed

Full-time

Part-time

Unemployed

Retired

Family care

Other

Occupational Class:

Professional

Intermediate

Routine

Marital Status:

Never married

Married / Cohab

Prev. married

Dep. Children

No

Yes
Age 19

0.01

0.79

0.01

0.00

0.00

0.04

0.14

0.08

0.34

0.58

0.95

0.05

0.00

0.98

0.02
Age 29

0.06

0.58

0.07

0.01

0.00

0.28

0.01

0.16

0.32

0.53

0.20

0.79

0.02

0.38

0.62
Age 39

0.08

0.58

0.16

0.01

0.01

0.15

0.02

0.21

0.28

0.52

0.09

0.86

0.05

0.24

0.76
Age 49

0.10

0.57

0.15

0.03

0.02

0.10

0.04

0.23

0.27

0.50

0.08

0.83

0.10

0.78

0.22
0.07
0.78
0.15

0.07
0.78
0.15

Age 59

0.10

0.31

0.14

0.03

0.26

0.08

0.09

0.24

0.25

0.51

0.98

0.02 
Table 2. Assessment of model fit for Latent Role Configurations across the life course using BIC, the Lo-Mendell-Rubin Likelihood Ratio Test, and Entropy Index

\begin{tabular}{|c|c|c|c|c|c|c|}
\hline Age & $\mathbf{N}$ & $\begin{array}{l}\text { Number } \\
\text { of Latent } \\
\text { Classes }\end{array}$ & Log likelihood & BIC & $\begin{array}{l}\text { Lo-Mendell-Rubin } \\
\text { Likelihood Ratio } \\
\text { Test p-value }\end{array}$ & $\begin{array}{l}\text { Entropy } \\
\text { Index }\end{array}$ \\
\hline \multirow[t]{3}{*}{19} & 1552 & 2 & -2239.901 & 4656.138 & 0.000 & 0.899 \\
\hline & & 3 & -2121.712 & 4522.611 & 0.732 & 0.802 \\
\hline & & 4 & -2106.457 & 4594.973 & 1.000 & 0.792 \\
\hline \multirow[t]{3}{*}{24} & 1552 & 2 & -3890.975 & 7972.979 & 0.000 & 0.937 \\
\hline & & 3 & -3726.796 & 7754.831 & 0.000 & 0.935 \\
\hline & & 4 & -3683.412 & 7778.273 & 0.000 & 0.793 \\
\hline \multirow[t]{4}{*}{29} & 1552 & 2 & -4059.455 & 8309.940 & 0.000 & 0.928 \\
\hline & & 3 & -3808.464 & 7918.167 & 0.000 & 0.869 \\
\hline & & 4 & -3780.751 & 7972.950 & 0.000 & 0.853 \\
\hline & & 5 & -3757.029 & 8035.716 & 0.506 & 0.874 \\
\hline \multirow[t]{3}{*}{34} & 1552 & 2 & -4008.146 & 8207.322 & 0.000 & 0.916 \\
\hline & & 3 & -3804.879 & 7910.997 & 0.000 & 0.857 \\
\hline & & 4 & -3774.705 & 7960.860 & 1.000 & 0.776 \\
\hline \multirow[t]{4}{*}{39} & 1552 & 2 & -4155.759 & 8502.547 & 0.000 & 0.909 \\
\hline & & 3 & -3985.305 & 8271.847 & 0.000 & 0.856 \\
\hline & & 4 & -3955.506 & 8322.461 & 0.000 & 0.751 \\
\hline & & 5 & -3941.790 & 8405.238 & 1.000 & 0.748 \\
\hline \multirow[t]{3}{*}{44} & 1552 & 2 & -4571.290 & 9333.610 & 0.000 & 0.910 \\
\hline & & 3 & -4480.107 & 9261.454 & 1.000 & 0.769 \\
\hline & & 4 & -4438.736 & 9288.921 & 1.449 & 0.672 \\
\hline \multirow[t]{3}{*}{49} & 1552 & 2 & -4570.384 & 9331.797 & 0.000 & 0.779 \\
\hline & & 3 & -4511.911 & 9325.060 & 0.954 & 0.864 \\
\hline & & 4 & -4473.047 & 9357.544 & 0.386 & 0.691 \\
\hline \multirow[t]{3}{*}{54} & 1506 & 2 & -4442.539 & 9075.326 & 0.000 & 0.705 \\
\hline & & 3 & -4383.790 & 9067.585 & 0.000 & 0.770 \\
\hline & & 4 & -4347.987 & 9105.737 & 1.000 & 0.805 \\
\hline \multirow[t]{3}{*}{59} & 1373 & 2 & -4155.460 & 8498.764 & 0.000 & 0.960 \\
\hline & & 3 & -4107.998 & 8512.211 & 0.031 & 0.908 \\
\hline & & 4 & -4065.240 & 8535.066 & 0.000 & 0.839 \\
\hline \multirow[t]{3}{*}{64} & 1191 & 2 & -3295.397 & 6774.940 & 0.000 & 0.973 \\
\hline & & 3 & -3268.453 & 6827.291 & 0.025 & 0.823 \\
\hline & & 4 & -3247.278 & 6891.178 & 0.000 & 0.747 \\
\hline
\end{tabular}


The following decision-making process was undertaken in deciding upon the number of LRCs at each age. Model selection was based on the log likelihood, BIC, LMR-LRT, entropy and interpretation of the conditional probabilities in each class. When disagreement occurred, the following guidelines were applied: we did not select any $t$-class solutions where a LRC contained fewer than 5 percent of the sample or where the difference between the BIC of the selected model and its neighboring $t-1$ class model was greater than 1 percent. Where the LMR-LRT did not agree with the BIC, we used entropy and model interpretation to balance these indicators. In early adulthood (age 19), the 3-class model had a nonsignificant LMR-LRT, which suggested the 2-class model provided a good fit. This was confirmed by the high entropy (Table 2) and the observation that the 3class solution included an LRC describing only 4 percent of the sample. Between the ages of 24 and 54 , the three-class model had the lowest BIC value and good entropy, and although the LMR-LRT did not always agree with the BIC and entropy, model interpretation suggested the 3-class models provided a good fit to the data. For example, at ages 29 and 39, the LMR-LRT indicated that a 4-class model might be preferable; however, interpretation of the LRCs at these ages suggested that the addition of a fourth LRC added little to our understanding of the combinations of work and family roles. Notably, the fourth class resulted from the division of one of the LRCs from the 3-class model, where the only distinguishing feature was a difference in occupational class. Since no other differences between the 3- and 4-class models were evident, the more parsimonious 3-class LRC was retained. As individuals approached retirement age (ages 59 and 64), the 2-class models had the lowest BIC values and the highest entropy. The LMR-LRT did not discriminate between the 2, 3 and 4-class models, but model interpretation confirmed that the 2-class models provided a good fit.

The conditional and unconditional probabilities of the LRCs identified in Table 2 are presented in Appendix A. The conditional probabilities of each LRC specify the likelihood of endorsing the possible categories of each life course domain given membership within that particular LRC, while the unconditional probabilities indicate the proportion of the sample in each LRC. For example, at age 19, the first LRC described the experiences of 7 percent of the sample. This group had a nearly equal probability of providing family care $(0.497)$ or working full-time (0.412), a high likelihood of being in a routine occupational class (0.716), a moderately high likelihood of being married (0.612), but were unlikely to have children (0.698). The second LRC, capturing the experiences of the majority of the sample (93\%) at this age, was characterized by a high likelihood of full-time employment $(0.828)$, work in a routine occupational class (0.567), and being single (0.994) with no children (1.00). Given the greater propensity of the first LRC to be providing family care, it is not surprising that this group was comprised almost exclusively of women (92 percent), while the second, larger group had a nearly equal gender distribution (49.2 percent female and 50.8 percent male).

Between the ages of 24 and 54, three LRCs best captured the most common configurations of work and family roles and begin to illustrate the gendered nature of role configurations. For instance, there was an all-female role configuration characterized by a high likelihood of marriage and of having dependent children through their mid- to late-forties. Here, the predominant labour activity varied across the age groups; family care was most likely for these women in their twenties, but the probability of working parttime increased in their mid- to late- thirties, continuing until the age of 54 at which time retirement or working in a full- or part-time capacity were the most probable activities. At all ages, these women were most likely to report being in a routine occupational class.

Strong attachment to the labour market was a consistent feature of the remaining two LRCs between the ages of 24 and 54 . Occupational class, marital status, and the likelihood of having children distinguished these two LRCs over the respondents' mid-twenties to their late-forties. One of the two LRCs at these ages predominantly reflected the experiences of men who combined full-time work and a nearly equal probability of being in a routine or nonroutine (professional or intermediate) occupational class (ages 24-34) or non-routine class (ages 39-44) with marriage and children. The remaining LRC, which captured the work and family roles of men and women, was distinguished by a low likelihood of marriage before mid-life, and a very low likelihood of 
ever having children. Here too respondents were more likely to report being in a non-routine occupational class by age 44 .

From later mid-life to retirement age (age 59-64) two LRCs described the work and family life experiences of respondents in this sample. An allmale LRC was characterized by ongoing strong labour market attachment through either full-time work or self-employment (although retirement was also likely by age 64), a nearly equal probability of being in a routine or non-routine class and high probability of being married. The second LRC predominantly described the experiences of women (99.9\%) who were likely to report a mix of retirement, full or parttime employment, or family care. They also had a nearly equal probability of being in a routine or nonroutine occupational class and a high likelihood of being married.

LRCs provide snapshots of the interconnected work and family experiences of men and women at various moments across the life course, allowing us to discern the most common combinations of roles in an efficient, but meaningful way. The LRCs also begin to delineate the gendered nature of life course experiences. Women who were married with children were much more likely to be providers of family care or work part-time from early- to mid-adulthood compared to their female counterparts who did not marry young or have children. In contrast, men who were married with children showed strong labour market attachment.

\section{Stage Two - Latent Life Pathways}

Latent life paths (LLPs) are the pathways or trajectories that connect role configurations from young adulthood to retirement age. They provide us with a picture of how the LRCs at different ages are linked together to represent experiences over time. The probabilities of moving between various role configurations as individuals age outline the key life course patterns of labour market attachment, occupational class, and family life over the entire span of 'working' years.
In this stage, the LRCs from the first stage were used as the observed variables at each age point across the life course (see Figure 2). A number of models were compared on the basis of goodness-offit indices and model interpretability (Table 3 ). While the LMR-LRT suggested that the 2-class model provided the best fit, the declining BIC in the 3-, 4-, and 5-class models, the high entropy and theoretical interpretation of the latent pathways, suggested that a 5-class model was most appropriate. On the basis of their defining labour market and family experiences over the life course, the five pathways are referred to here as: (1) Career Focused Females; (2) Career Focused Males; (3) Career Transition; (4) Family Carers and Part-time Workers; and (5) Workers with Families.

The unconditional and conditional probabilities for the five LLPs are presented in Table 4. The unconditional probabilities indicate the proportion of the sample best described by that particular path, while the conditional probabilities specify the likelihood of transitioning to and from role configurations given membership in that particular pathway. Since the LLPs modeled in this work begin at age 19 , the conditional probabilities at this age represent a starting point. For example, individuals in the Career Focused Females group had a high likelihood of being in the second LRC (0.983) at age 19 and were likely to transition to the third LRC at age 24 (0.969), followed by the second LRC at age 29 (0.979). For ease of interpretation, expected role probabilities within each latent life path are presented in Figures 3a-e. For simplicity, we present only the expected role probabilities for the most common labour market activities (full-time, part-time, family care and retirement) and family roles (single, married/cohabiting, presence of children in the household). These probabilities are the product of the conditional probability of a LRC within a latent life path and the conditional probability of a role within a LRC, summed over the LRCs at each age (Macmillan \& Eliason, 2003). In what follows, the five latent life pathways are briefly described. 
Table 3. Assessment of model fit for Latent Life Paths using BIC, the Lo-Mendell-Rubin Likelihood Ratio Test, and Entropy Index

Number of Latent Life Paths

1

2

3

4

5

6
Log likelihood

$-13199.330$

$-8501.617$

$-7922.161$

$-7540.588$

$-7254.142$

$-7039.206$
BIC

Lo-Mendell-Rubin

Likelihood Ratio

(LMR-LRT)

$p$-value

26523.563

17260.390

16233.730

15602.835

15162.194

14864.572
0.000

0.997

0.295

0.968

0.944

0.740

0.971

0.594

0.943 
Table 4. Unconditional and Conditional Probabilities for Latent Life Paths across the life course

Unconditional Probabilities of the 5-Class Latent Life Paths:

$\begin{array}{lll}\text { Career Focused } & \text { Career Focused } & \text { Career } \\ \text { Women } & \text { Men } & \text { Transition }\end{array}$

Family Care

Workers

Women

Providers with Families and $\mathrm{P} /$ Time

Workers

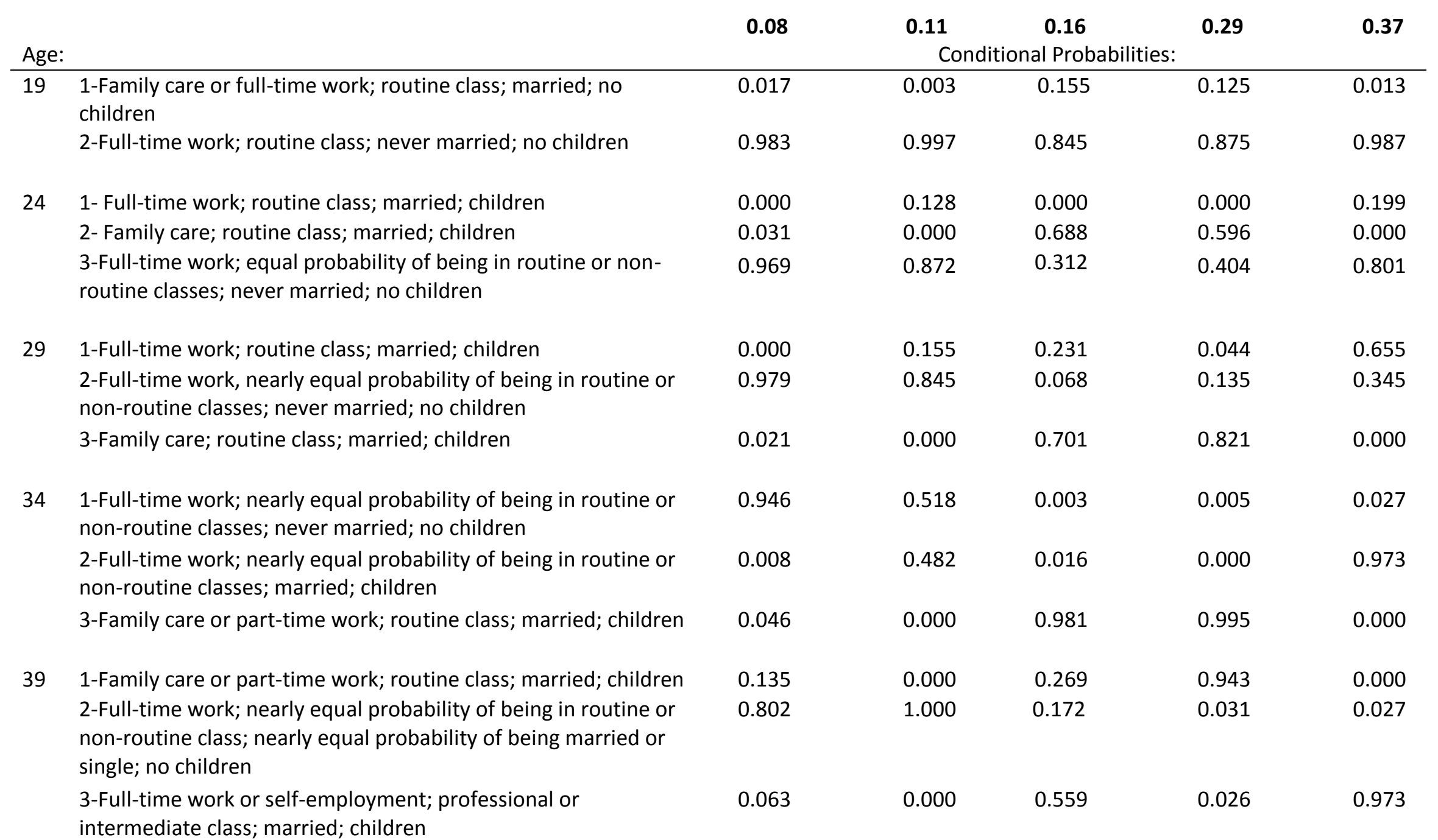


(Table 4 cont'd)

44 1-Part-time work or family care; routine class; married; children 2-Full-time work or self-employment; professional or intermediate class; married; children

3-Full-time work; intermediate or professional class; married no children

49 1-Full-time work or self-employment; routine class; married; children

2-Part-time work or family care; routine class; married; no children

3-Full-time work; intermediate or professional class; married; no children

54 1-Full-time work; routine class; married; no children 2-Full-time work or self-employment; professional or intermediate class; married; no children

3-Part-time work, full-time work, or family care; routine class; married; no children

59 1-Full-time work, retirement, self-employment or other; nearly equal probability routine/non-routine class; married; no children

2-Retired, part or full-time work, or family care; equal probability of routine or non-routine class; married; no children

64 1-Retired, full-time work or other activity; routine class; married; no children

2-Retired, part-time work or family care; equal probability of routine/non-routine class; married; no children
0.973

0.566

0.006

0.066

0.000

0.092

0.273

0.000

0.095

0.908

0.000

0.661

1.000

0.053

0.666

0.000

0.632

0.000

0.000

0.051

0.547

0.368

0.206

0.949

0.453

0.808

0.000

0.794

0.000

0.000

1.000

0.000

0.000

0.998

1.000

0.000

1.000

1.000

0.002

0.000

1.000

0.000

0.000

0.998

1.000

0.000

1.000

1.000

0.002 
Career Focused Females The first LLP, referred to here as Career Focused Females, described 8 percent of the sample and was nearly exclusive to the experiences of women (99\%). Full-time work was the predominant labour market activity for this group until their mid- to late-forties, at which time there was a slight increase in the probability of working part-time, providing family care, or being retired (Figure 3a). Occupational class was fairly stable across the span of working years, with a nearly equal probability of reporting a routine or non-routine occupational class. In terms of family life, the Career Focused Females had a low probability of marriage before their mid- to late-thirties and a low likelihood of ever having children. Just under half of those characterized by these work and family experiences (47 percent) were from the oldest cohorts (born 1927-1931), 34 percent were born in the middle cohorts (born 1932-1936), and only 19 percent were from the youngest cohorts (born 1937-1940).

Career Focused Males The second LLP, entitled Career Focused Males (Figure 3b), was nearly exclusive to the experiences of men (99\%). This group had a high probability of working full-time for much of their lives and the decline in the likelihood of fulltime employment in their later mid-life coincided with an increase in the likelihood of self-employment (not shown) and retirement (by age 64). Being in a routine occupational class was commonplace in early adulthood, but there was a modest increase in the probability of being in a professional class over the span of working years. Marriage was less common before their mid- to late thirties and with the exception of a slight increase in the likelihood of having children between their late twenties and midthirties, their likelihood was otherwise quite low. Nearly half (44 percent) of this group was from the oldest birth cohorts (born 1927-1931), one quarter from the middle cohorts (born 1932-1936) and 31 percent from the youngest cohorts (1937-1940).

Career Transition The third LLP, the Career Transition group, captured the experiences of 16 percent of this sample and was comprised exclusively of women (Figure 3c). Their high likelihood of working full-time as young adults declined in their $20 \mathrm{~s}$ and $30 \mathrm{~s}$ as the probability of providing family care increased. This transition was temporary though, with an increased probability of working full-time evident again from their mid- to late-thirties until their midfifties. By their mid-fifties, a mix of retirement and part- and full-time work characterized the labour market activity of this group, with retirement becoming increasingly likely as they moved into their later fifties and early sixties. Although this group was likely to report being in a routine occupational class as young adults and during their years as caregivers, the likelihood of being in a professional occupational class rose slightly through mid-life. These women had a high probability of being married for much of their working years, with only a slightly higher likelihood of being previously married by their mid-sixties (not shown), and were likely to have dependent children in the household between their mid-twenties and late thirties. The cohort distribution of this group was fairly even across the three birth cohorts, with 31,36 and 33 percent of the sample born in the oldest, middle, and youngest cohorts, respectively.

Family Carers and Part-Time Workers The fourth LLP-the Family Carer and Part-Time Workers group-was also exclusive to the experiences of women, and captured the work and family life of 29 percent of the sample (Figure 3d). Family care was the dominant labour market activity of this group in their 20s and 30s, followed by an increase in the probability of working part-time. By age 54, the probability of retirement began to increase. Given their more limited formal labour market attachment, this group was likely to be in a routine occupational class for most of their working years, although there was a slight increase in the probability of being in a professional occupational class as they neared retirement age. The Family Carers and Part-Time Workers were likely to be married by age 24 and remain married, as well as to have dependent children in the household from their mid-twenties to mid-forties. Again, the birth cohort distribution was quite even across the three groups: 31,37 , and 32 percent of this group belonged to the oldest, middle, and youngest birth cohorts.

Workers with Families The final pathway, Workers with Families characterized the experiences of 37 percent of the sample (Figure 3e), most of whom were men (99 percent). Consistent full-time work, including self-employment from their mid-40s to late 50s, characterized much of the working lives of this group, with retirement, an 'other' activity or full- 
time work being most common by age 64 . In terms of occupational class, these men had a nearly equal probability of being in the routine or non-routine classes across the life course, although the likelihood of being in a professional occupational class showed a modest increase with age until their mid-fifties. Unlike males in the 'Career Focused Males' group, the consistent, full-time labour market attachment characteristic of this group was coupled with a high likelihood of being married by age 29 and remaining married, as well as having children in the household between their late $20 \mathrm{~s}$ and mid-40s. Thirty-two percent of this group was born between 1927 and 1931, while 35 and 33 percent were born in the middle and youngest cohorts, respectively.

LLPs provide an innovative way of summarizing the multi-dimensional trajectories of men and women from early adulthood to retirement age through probabilistic pathways. The two-stage approach not only captures the interdependencies between work and family roles, but also highlights the gendered nature of life course experiences for these cohorts of older adults. With the exception of one opposite sex individual in three of the life paths (Career Focused Females, Career Focused Males, and Workers with Families), the life paths were distinctly gendered. For women, only a small proportion ( $8 \%$ - the Career Focused Females) participated in full-time work continuously, most likely owing to their very low likelihood of having children. For women with families, a combination of family care and part-time work was most common when dependent children were still in the household. Conversely, men's strong labour market attachment was unaffected by marriage or the presence of children.

In terms of the birth cohort composition among the life paths, there was a fairly even distribution of birth cohorts in all life paths, with the exception of the two Career Focused groups, who were comprised of a larger proportion of the older cohorts ( 47 and 44 percent). Members of the oldest cohorts reached young adulthood in the years immediately following the end of the Second World War. Women may have been less likely to marry young because of high warrelated mortality, resulting in fewer eligible partners, and men may have delayed family formation or not had children at all due to other war-related factors, such as ongoing demobilization, war-related disability, etc. Also, policies that discouraged women's labour market participation, consistent with recommendations outlined in the Beveridge Report (Beveridge, 1942), would have had a greater impact on women in the younger birth cohorts because they reached working age in the years following their implementation. Thus, in light of social policies and provisions that inhibited women from being careeroriented, it follows that fewer of the women in these younger cohorts reported strong labour market attachment relative to their older counterparts. 


\section{Figure 3. Expected role probabilities by Latent Life Path}

\section{a. Latent Life Path I: Career Focused Women}
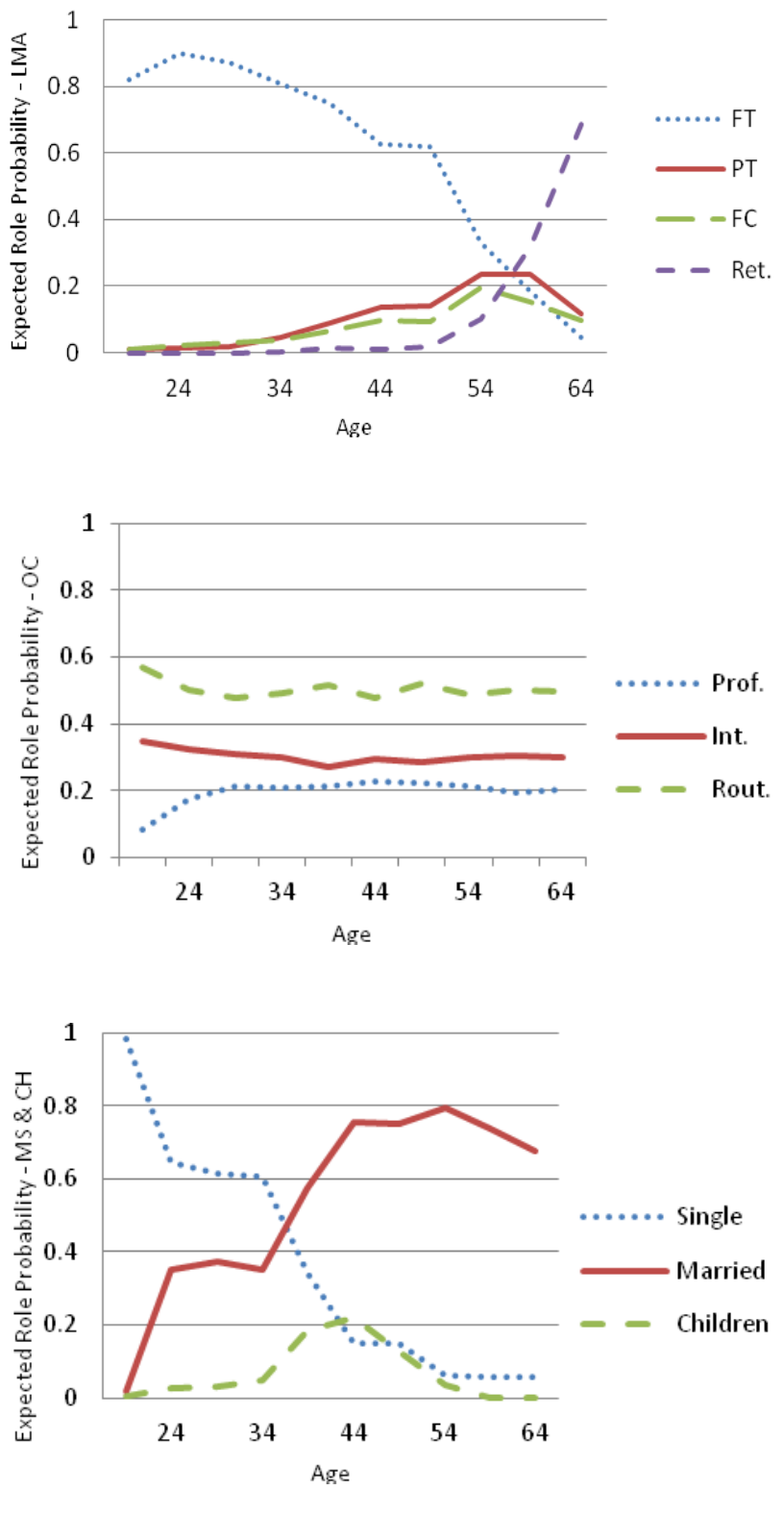

b. Latent Life Path II: Career Focused Men
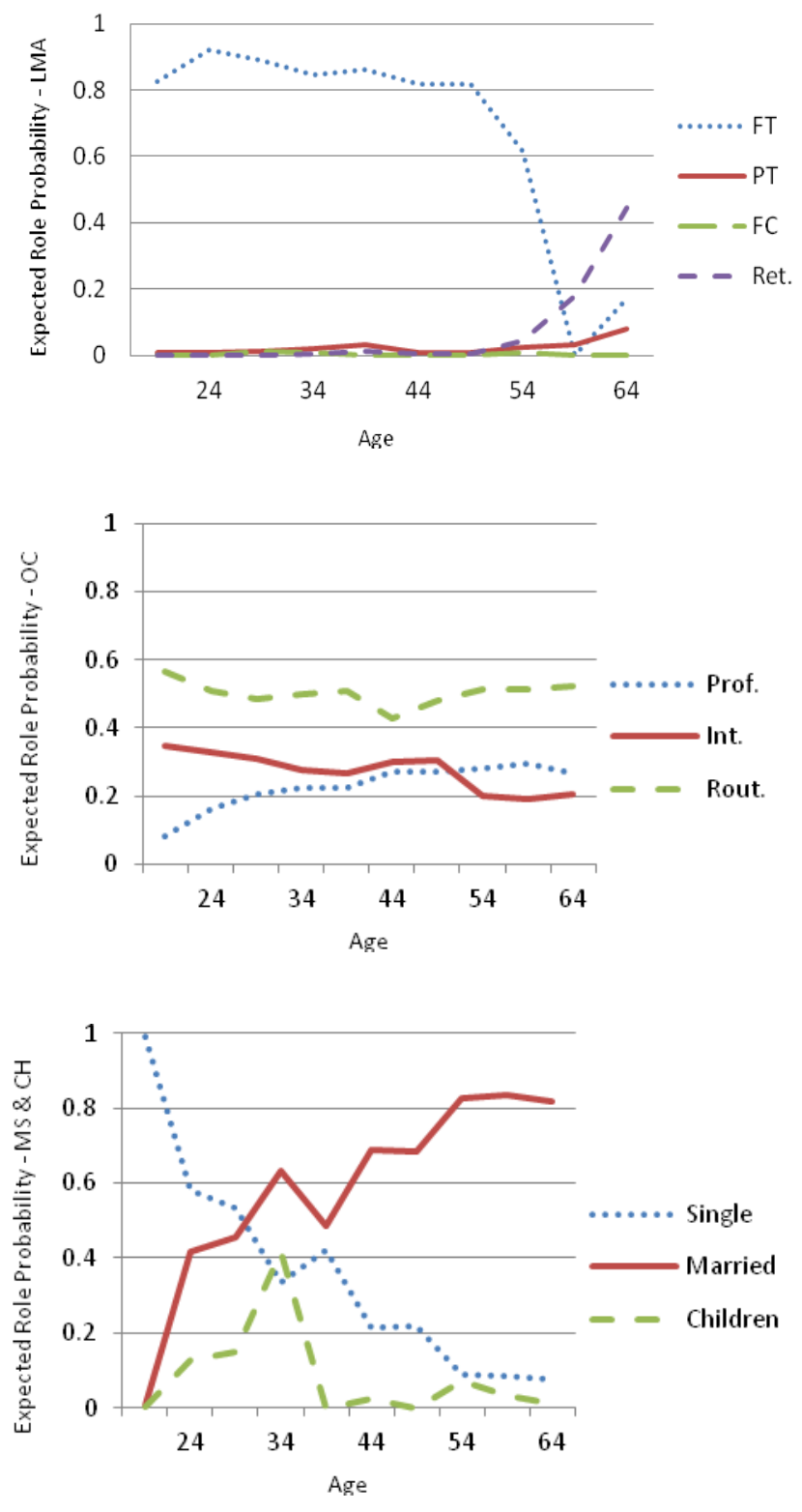
(Figure 3 cont'd) $^{\prime}$

\section{c. Latent Life Path III: Career Transition}
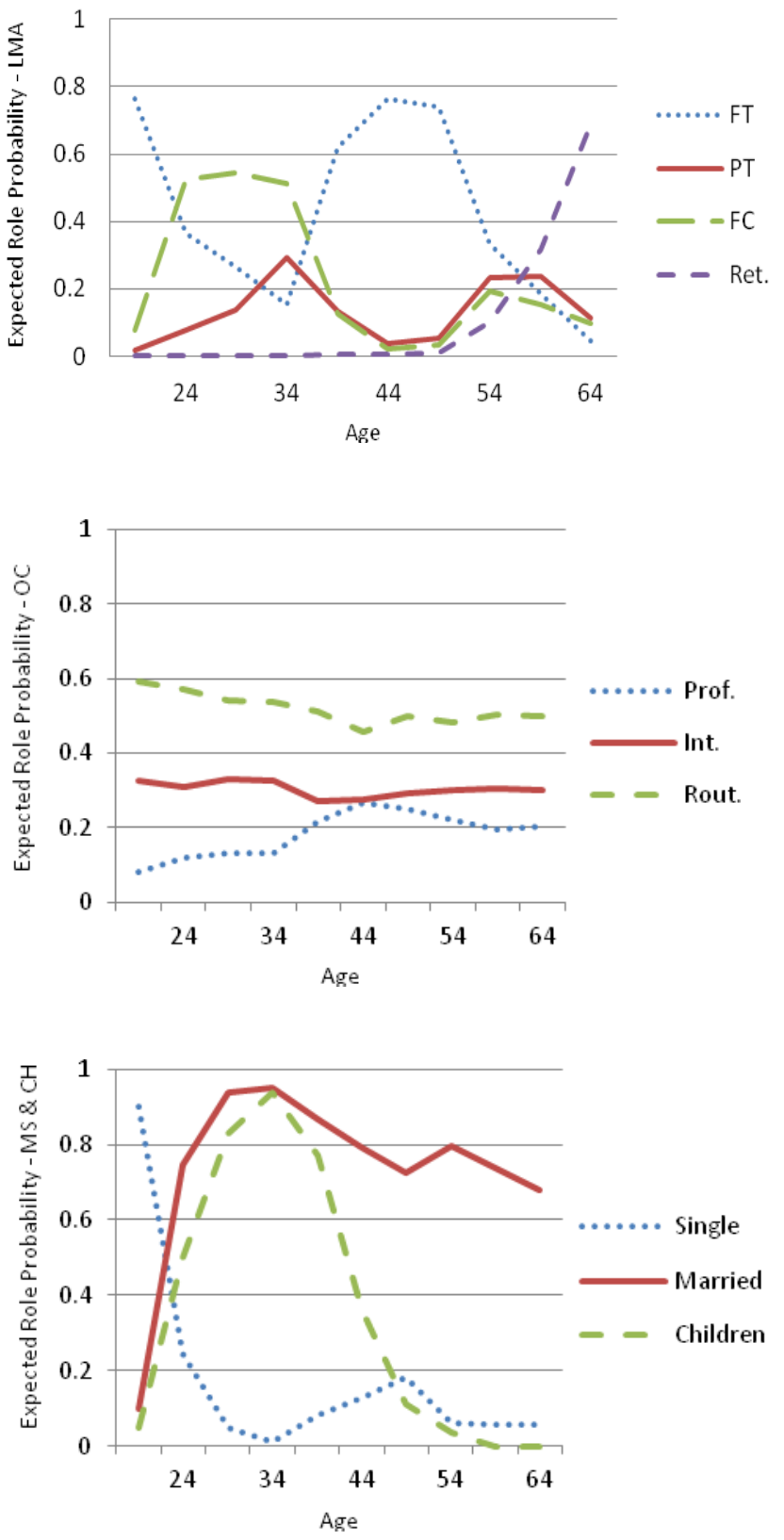

\section{d. Latent Life Path IV: Family Carers and Part-time} Workers
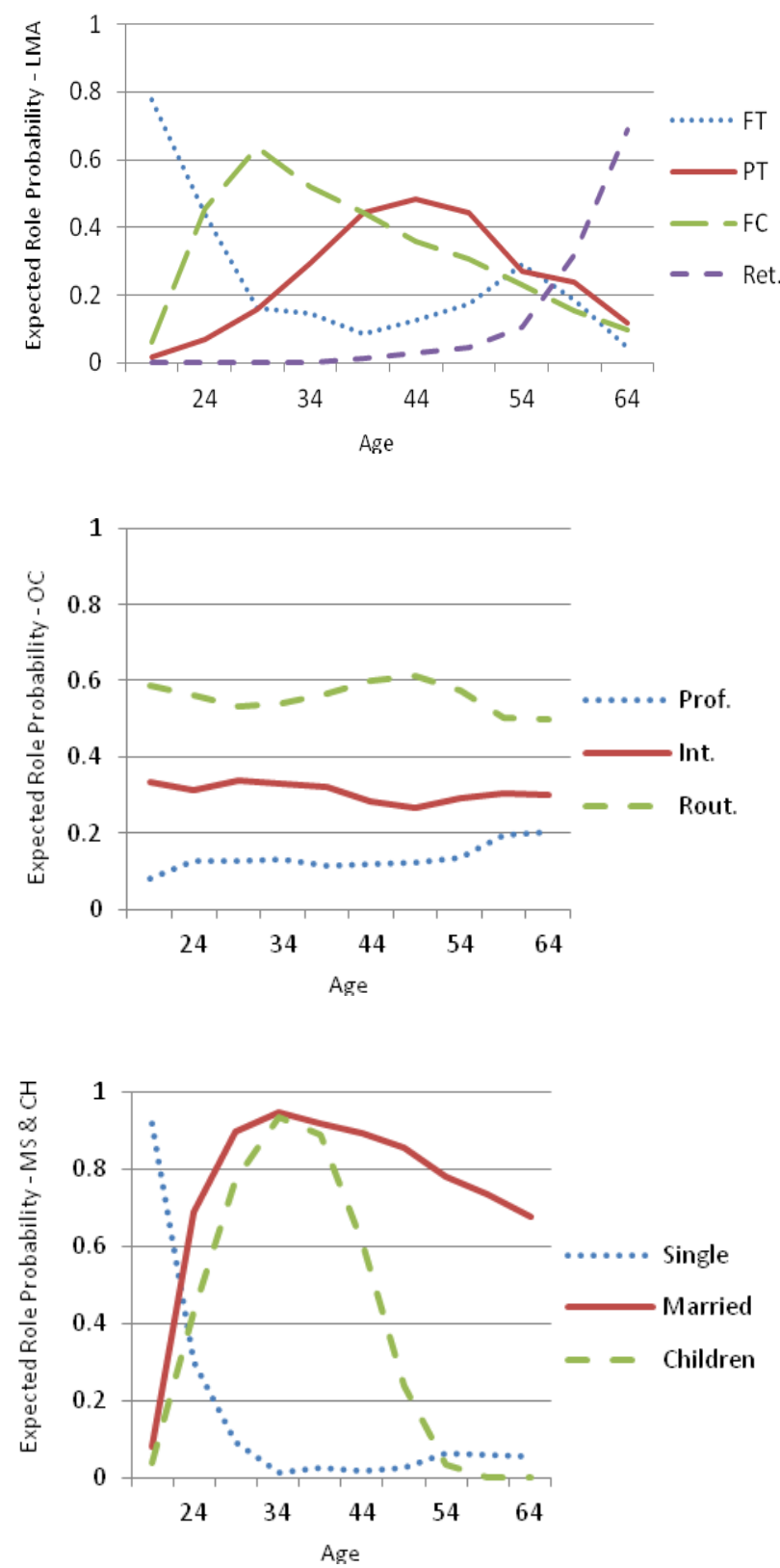
(Figure 3 cont'd) $^{\prime}$

e. Latent Life Path V: Workers with Families
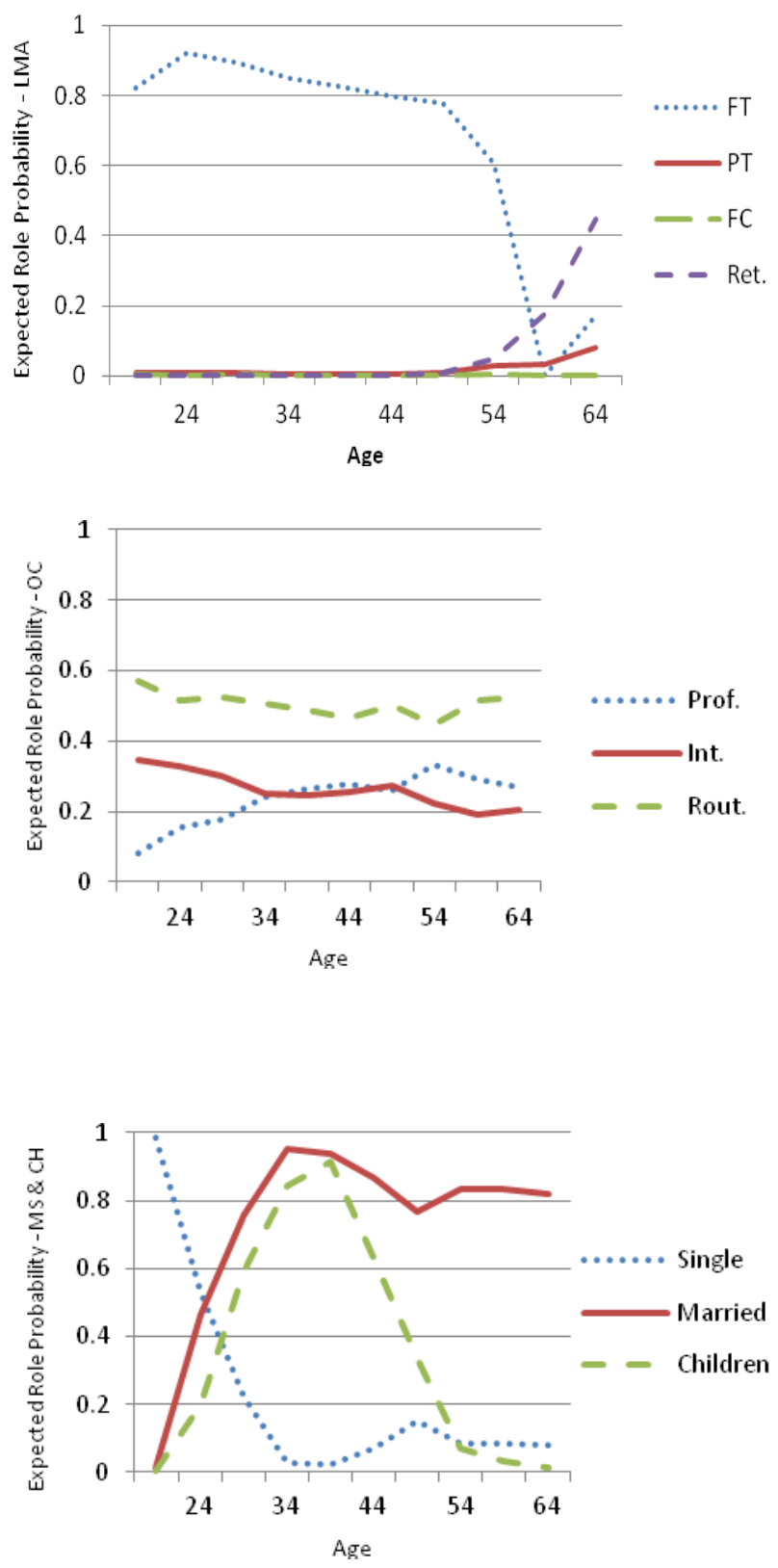

Note. LMA - labour market activity; OC occupational class; MS - marital status; $\mathrm{CH}$ - children

\section{Latent Life Paths and outcomes in later life}

In the final part of the analysis, we assess the relationship between the LLPs identified here and economic and health outcomes at age 65 (Table 5). Significant mean differences in all three types of income were evident, with the Workers with Families faring the best in all cases, followed by the Career Focused Males. Among the three LLPs describing women's work and family experiences, the Career Focused Females reported the highest income levels, followed by the Career Transition LLP and the Family Carers and Part-time Workers. Overall differences in pension income were particularly marked, with men in the Workers with Families latent path reporting more than four times the amount reported by women who were primarily caregivers and part-time workers (Family Carers and Part-time Workers).

In terms of health at age 65, significant differences by the latent life paths were noted for mental health only. The Career Transition group reported the greatest mental health problems, followed by the women in the Family Carers and PartTime Workers and Career Focused Females groups. Men in the Career Focused Males and the Workers with Families groups reported significantly fewer mental health problems overall. 
Table 5. F-Tests of Mean Differences in measures of income and health at age 65 by Latent Life Paths

Income at Age 65:

Benefit income:

Pension income:

Labour income

GHQ (Mental health problemst):

Count of chronic health problems

Full Sample

Career Focused Females

Career Focused Males

Career Transition

Family Carers \& Part-time Workers

Workers with Families

Full Sample

Career Focused Females

Career Focused Males

Career Transition

Family Carers \& Part-time Workers

Workers with Families

Full Sample

Career Focused Females

Career Focused Males

Career Transition

Family Carers \& Part-time Workers

Workers with Families

Full Sample

Career Focused Females

Career Focused Males

Career Transition

Family Carers \& Part-time Workers

Workers with Families

Full Sample

Career Focused Females

Career Focused Males

Career Transition

Family Carers \& Part-time Workers

Workers with Families
Mean

(Std. Deviation)

(Income in f2005)

$3,886(2,270)$

$3,499(1,841)$

$4,324(2,050)$

$3,293(2,102)$

$2,877(2,080)$

$4,886(2,193)$

$3,568(6,261)$

$3,639(4,147)$

$4,878(6,170)$

$2,359(3,218)$

$1,169(2,244)$

$5,546(8,642)$

$1,431(6,200)$

$882(3,656)$

$2,241(9,051)$

$804(2,721)$

$433(1,849)$

$2378(8,467)$

$10.6(4.8)$

$10.8(4.1)$

$10.3(4.6)$

$11.5(5.8)$

$11.4(5.0)$

$9.6(4.2)$

$1.5(1.2)$

1.7 (1.4)

$1.4(1.2)$

$1.5(1.2)$

$1.5(1.2)$

$1.4(1.2)$
Difference Test

$\mathrm{F}=45.32 * * *, \mathrm{df}=4$

$F=25.98^{* * *}, \mathrm{df}=4$

$\mathrm{F}=5.46 * * *, \mathrm{df}=4$

$\mathrm{F}=8.53^{* * *}, \mathrm{df}=4$

$F=1.28, d f=4$

+ Higher GHQ scores indicate greater mental health problems. 


\section{Discussion}

The potential combinations of labour market and family roles over the span of 'working' years were numerous, reflecting the complexity and diversity of individual experience in these domains. Yet, capturing this complexity may be instructive for assessing differences across cohorts, social contexts and various social groups, as well as for understanding later life outcomes, such as health and economic resources. Empirically, the task of summarizing the detailed roles and experiences of individuals in multiple life course domains over considerable periods of the life course has presented particular methodological challenges stemming from the movement into and out of roles, and the importance of simultaneously considering experiences in multiple life course domains. The latent class approach applied here facilitated understanding the most common configurations of work and family roles at particular ages, and over the entire span of 'working' years, providing a picture of the most likely work and family experiences for this group of older adults. To our knowledge, this is the first study to model life course experiences in multiple domains over such a substantial portion of the life course using latent class models.

Consistent with the normative and institutionally supported gender division of labour during this period of time in Britain, the LRCs and LLPs demonstrated distinctly gendered patterns of work and family life. The LLPs derived here also confirm the strong interdependencies between family roles and formal labour market participation, particularly for women. Indeed, only a small proportion of women (8\%) exhibited the strong labour market attachment (the Career Focused Females) that was characteristic of men's 'working' years, most likely owing to this particular group's tendency to marry later and not ever have children. Conversely, men's working lives were uninterrupted by marriage and the presence of children in the household. To be sure, the findings reported here are relevant to the cohorts of British older adults under study. In particular, these individuals entered the labour market during a period of time characterised by growth in part-time labour market opportunities for married women as well as high fertility. Cohorts preceding the groups considered here might have had more interrupted labour market experiences owing to World War II. Likewise, the higher educational attainment of later cohorts would have been likely to shape the work and family experiences differently. For women in particular, the postponement of motherhood for longer initial periods of full-time work, as well a higher likelihood of combining motherhood with continuous work, would be expected in later cohorts. Despite these anticipated differences, the approach applied here would generalise across cohorts and contexts and represents an ideal method for cohort comparisons of men's and women's work and family lives over time. Foregrounding observed life course experiences with the social policy context is important for understanding the opportunities and constraints placed on individual choices, and for addressing the tension between agency and structure that the life course perspective aims to understand.

LLPs also provide a promising means by which life course researchers can begin to ask more detailed questions concerning the influence of life course experiences on outcomes in later life. Mean differences in health and economic outcomes by the latent life paths confirm well-known gender differences in economic resources (Dex et al. 2000; Mumford \& Smith 2004; Rake 2000) and add to the mixed findings regarding the relationship between gender and health (Arber \& Cooper 1999; Suen 2011). However, this approach goes one step further by not assuming homogeneity within men's and women's experiences. Indeed, our findings indicate that there is heterogeneity among the experiences of women, and that these differences have implications for health and economic resources in later life. For example, women with stronger labour market attachment and fewer caregiving responsibilities fared significantly better financially than women who were married with children and whose primary labour market activity was a combination of family care and part-time work. Differences were also evident between women who returned to the labour market on a full-time vs. part-time basis following periods of family care, with the former group reporting greater benefit, pension and labour income. In terms of health, women who left the formal labour market for a period of time to provide care for their families and returned in their late thirties (women in the Career 
Transition group) had more mental health problems than women without children who had stronger ties to the labour market (Career Focused Females). Interestingly, there were not significant differences between the two groups that characterized the experiences of men (Career Focused Males or Workers with Families), suggesting that family circumstances do not matter for men's economic circumstances and health at retirement age to the same extent that they do for women. The noted differences among the LLPs describing women's work and family lives warrant further explanation to determine how these experiences shape economic and health outcomes, as well as what intermediary factors might help account for these associations.

Advancing research in this area would also benefit from a comparison of the findings presented here with other methodological approaches. One such method is sequence analysis, which has increasingly been applied to the study of life course trajectories (e.g., Abbott 1995; Abbott and Tsay 2000; Aisenbrey \& Fasang 2010).

Although studies of the life course are certainly not novel, the challenges associated with summarizing or modeling life course experiences in multiple domains has meant that analyses have often been restricted to particular phases of the life course, such as the transition to adulthood (Aassve, Billari, \& Piccarreta, 2007; Macmillan and Copher 2005; Pollock 2007), or the progression through various stages of only one life course domain, such as career development (e.g., Scherer 2001). Fortunately, the detailed life course history data collected in the second and third waves of the BHPS afforded the opportunity to look at life course experiences from late adolescence to early old age. However, the findings reported here should be considered in light of the limitations of the approach. First, we were limited by the availability of the observed data used in the latent class models. For example, dependent children were defined as being younger than 16 years because of limitations in the data. However, the presence of older children may also influence men's and women's labour market involvement. Additionally, more detailed occupational data might have resulted in more detailed LRCs at the selected ages across the life course.
A second consideration involves our decision to model LRCs at 5-year intervals in the first stage of the analysis, a decision that was made with the aim of striking a balance between capturing key life course transitions and feasibility in terms of model estimation. While we anticipate that a shorter interval would have very little effect on the longer term LLPs derived here, it remains an empirical question. Similarly, the use of modal labour market and occupational class to classify the entire year may have overlooked short-term changes, such as brief spells of unemployment. Again, while we would not expect to see considerable differences in our findings, future work might examine trajectories using monthly rather than yearly intervals.

Notwithstanding these limitations, given the challenges associated with empirically summarizing life course histories, the approach adopted here represents an important methodological contribution to the study of life course processes and their association with late life outcomes. Importantly, modeling life course experiences in a latent variable framework facilitated the identification of meaningful subgroups or configurations of experience, and as such, addresses one of the key challenges associated with this type of analysis - the issue of how to deal with the very large number of possible observed role combinations and life pathways. To our knowledge, this is the first study to simultaneously examine experiences in multiple social roles over a substantial period (46 years) of the life course, while incorporating the influence of gender and birth cohort. Moreover, by considering the observed labour market and family experiences in the social policy context in which they unfolded, this study provides insight into the ways in which the policies and provisions of particular historical periods shape men's and women's experiences differently, as well as the heterogeneity of experiences among groups of women and men. Accordingly, this research bridges theoretical concerns with respect to the life coursethe notion of linked lives, the importance of context, and the tension between agency and structure-with appropriate analytical methods for tackling such questions. 


\section{Acknowledgements}

Corna was supported by a Canadian Institutes of Health Research Postdoctoral Fellowship and Sacker was supported by an Economic and Social Research Council grant RES-596-28-0001. The BHPS was made available through the UK DATA Archive and were originally collected by the Economic and Social Research Council Research Centre on Microsocial Change at the University of Essex, which is now incorporated with the Institute for Social and Economic Research.

\section{References}

Aassve, A., Billari, F. C., \& Piccarreta, R. (2007). Strings of adulthood: A sequence analysis of young British women's work-family trajectories. European Journal of Population, 23, 369-388.

Abbott, A. (1995). New methods for old ideas. Annual Review of Sociology, 21, 93-113.

Abbott, A., \& Tsay, A. (2000). Sequence analysis and optimal matching methods in sociology. Review and prospect. Sociological Methods and Research, 29, 3-33.

Aisenbrey, S., \& Fasang, A. E. (2010). New life for old ideas: The "second wave" of sequence analysis. Bringing the "course" back into the life course. Sociological Methods \& Research, 38, 420-462.

Amato, P. R., Landale, N. S., Havasevich-Brooks, T. C., \& Booth, A. (2008). Precursors of young women's family formation pathways. Journal of Marriage and Family 70, 1271-1286.

Arber, S., \& Cooper, H. (1999). Gender differences in health in later life: The new paradox? Social Science \& Medicine, 48, 61-76.

Beveridge, Sir W. (1942). Social insurance and allied services. London, England: His Majesty's Stationery Office.

Celeux, G., \& Soromenho, G. (1996). An entropy criterion for assessing the number of clusters in a mixture model. Journal of Classification, 13, 195-212.

Clark, S. L., \& Muthén, B. (2009). Relating latent class analysis results to variables not included in the analysis. Submitted for publication.

Creighton, C. (1999). The rise and decline of the 'male breadwinner family' in Britain. Cambridge Journal of Economics, 23, 519-41.

Dex, S., Sutherland, H., \& Joshi, H. (2000). Effects of minimum wages on the gender pay gap. National Institute Economic Review, 173, 80-90.

Dannefer, D. (2003). Cumulative advantage/disadvantage and the life course: Cross-fertilizing age and social science theory. Journal of Gerontology: Social Sciences, 6, S327-S337.

Elder, G. H. Jr. (1985). Perspectives on the Life Course. In G. H. Elder (Ed.), Life Course Dynamics (pp. 23-49). Ithaca: Cornell University Press.

Elder, G. H. Jr., Kirkpatrick Johnson, M., \& Crosnoe, R. (2003). The emergence and development of life course theory. In J. T. Mortimer \& M. J. Shanahan (Eds.) Handbook of the Life Course (pp. 3-18). Hingham: Kluwer Academic Publishers.

Feldman, B. J., Masyn, K. E., \& Conger, R. D. (2009). New approaches to studying problem behaviors: A comparison of methods for modeling longitudinal, categorical adolescent drinking data. Developmental Psychology 45, 352-676.

George, L. K. (1996). Missing links: the case for a social psychology of the life course. The Gerontologist 36, 248255.

Goldberg D. P., \& Williams, P. (1988). A user's guide to the general health questionnaire. Windsor: NFER-Nelson.

Lazarsfield, P. F., \& Henry, N. W. (1968). Latent structure analysis. Boston: Houghton Mifflin.

Leisering, L. (2003). Government and the lifecourse. In J. T. Mortimer \& M. J. Shanahan (Eds.) Handbook of the Life Course (pp. 205-225). Hingham: Kluwer Academic Publishers.

Lewis, J. (1992). Gender and the development of welfare regimes. Journal of European Social Policy, 2, $159-173$.

Lewis, J. (2001). The decline of the male breadwinner model: implications for work and care. Social Politics, 8 , 152-169

Lo, Y., Mendell, N. R., \& Rubin, D. B. (2001). Testing the number of components in a normal mixture. Biometrika, 88, 767-778.

Macmillan, R., \& Copher, R. (2005). Families in the life course: Interdependency of roles, role configurations, and pathways. Journal of Marriage and Family, 67, 858-879.

Macmillan, R., \& Eliason, S. R. (2003). Characterizing the life course as role configurations and pathways. A latent structure approach. In J. T. Mortimer \& M. J. Shanahan (Eds.) Handbook of the Life Course (pp. 529554). Hingham: Kluwer Academic Publishers. 
Maggs, J. L., Jager, J., Patrick, M. E., \& Schulenberg, J. (2012). Social role patterning in early adulthood in the USA: Adolescent predictors and concurrent wellbeing across four distinct configurations. Longitudinal and Life Course Studies, 3, 190-210.

Magidson, J., \& Vermunt, J. K. (2004). Latent class models. In D. Kaplan (Ed.), The sage handbook of quantitative methodology for the social sciences (pp. 175-198). Thousand Oaks: Sage Publications.

Maré, D. C. (2006). Constructing consistent work-life histories: A guide for users of the British Household Panel Survey. ISER Working Paper 2006-39. Colchester: University of Essex.

Marshall, V. W., \& Mueller, M. M. (2003). Theoretical roots of the life-course perspective. In W.R. Heinz and V.W. Marshall (Eds.) Social Dynamics of the Life Course: Transitions, Institutions, and Interrelations (pp. 332). Hawthorne, NY: Aldine de Gruyter.

Mumford, K., \& Smith, P. N. (2004). The gender earnings gap in Britain. Discussion Paper No. 1109. Bonn: Institute for the Study of Labour.

Muthén, L. K., \& Muthén, B. O. (2010). MPlus Statistical Analysis with Latent Variables: User's Guide $\left(5^{\text {th }}\right.$ Edition ed.). Los Angeles: Muthén and Muthén.

Nylund, K. L., Asparouhov, T., \& Muthén, B. O. (2007). Deciding on the number of classes in latent class analysis: A monte carlo simulation study. Structural Equation Modeling, 14, 535-569.

Office for National Statistics. (2005). Reduced method NS-SEC analytic classes. Accessed $25^{\text {th }}$ October 2010 from http://www.ons.gov.uk/about-statistics/classifications/current/ns-sec/deriving/derivationtables/index.html

Office for National Statistics. (2012). CPI and RPI Reference Tables, September 2012. Accessed $24^{\text {th }}$ September 2012 from http://www.ons.gov.uk/ons/rel/cpi/consumer-price-indices/september-2012/index.html

O'Connor, J. S., Orloff, A. S., \& Shaver, S. (1999). States, Markets, Families - Gender, Liberalism and Social Policy in Australia, Canada, Great Britain and the United States. Cambridge: Cambridge University Press.

O'Rand, A. M. (1996). The precious and the precocious: Understanding cumulative disadvantage and cumulative advantage over the life course. The Gerontologist, 36, 230-238.

Pedersen, S. (1993). Family, Dependence and the Origins of the Welfare State: Britain and France, 1914-1945. Cambridge: Cambridge University Press.

Pevalin, D. J. (2000). Multiple applications of the GHQ-12 in a general population sample: An investigation of long-term retest effects. Social Psychiatry and Psychiatric Epidemiology, 35, 508-512.

Pollock, G. (2007). Holistic trajectories: A study of combined employment, housing and family careers using multiple-sequence analysis. Journal of the Royal Statistical Society A, 170, 167-183.

Räikkönen, E., Kokko, K., Chen, M., \& Pulkkinen, L. (2012). Patterns of adult roles, their antecedents and psychosocial wellbeing. Correlates among Finns born in 1959. Longitudinal and Life Course Studies, 3, 211227.

Rake, K. (2000). Women's Incomes over the Lifetime. Report to the Women's Unit, Cabinet Office. London: The Stationery Office.

Rose, D., \& Pevalin, D. (Eds). (2003). A Researcher's Guide to the National Statistics Socio-Economic Classification. London: Sage.

Scherer, S. (2001). Early career patterns: A comparison of Great Britain and West Germany. European Sociological Review, 17, 119-144.

Schulenber, J., \& Schoon, I. (2012). The transition to adulthood across time and space: overview of the special section. Longitudinal and Life Course Studies, 3, 164-172.

Suen, Y. T. (2011). Do older women or older men report worse health? Questioning the 'sicker' older women assumption through a period and cohort Analysis. Social Theory and Health, 9, 71-86.

Taylor, M. F. (Ed.) with Brice, J., Buck, N., \& Prentice-Lane, E. (2010). British Household Panel Survey User Manual Volume A: Introduction, Technical Report and Appendices. Colchester: University of Essex. 